MODELING, IDENTIFICATION AND CONTROL, 1981, VOL. 2, NO. 4, 201-223

doi:10.4173/mic.1981.4.2

\title{
A study of the $\mathbf{M}_{2}$ tide in the ice-covered Arctic Ocean $\dagger$
}

\author{
ZYGMUNT KOWALIK $\$ \S$
}

Keywords: hydrodynamics, $M_{2}$ tide, ice mechanics, numerical methods, Arctic Ocean, Barents Sea.

A model to study $\mathbf{M}_{2}$ tide propagation in the Arctic Ocean based on the equation of motion of the water and the pack ice, is considered. The mechanics of the ice floe interaction is described by the non-linear viscous constitutive law. Various empirical parameters entering the constitutive law are checked against the tideinduced motion of the pack ice. The distribution of the amplitude, phase, current ellipse in the ice-free and the ice-covered Arctic Ocean is computed and presented in figures. Special attention is given to clarifying the distribution and peculiarities of tide propagation in the Barents Sea. The tide-induced motion of the pack ice has been studied carefully; numerous experiments show that residual (over tidal period) ice drift is observed due to the non-linear ice floe interaction. It is found that both residual ice drift and periodical ice motion may lead to ice redistribution, setting the areas of ice convergence and divergence.

\section{Introduction}

The problem of the $\mathbf{M}_{2}$ tide distribution in the Arctic Ocean, solved by Kowalik and Untersteiner (1978), is considered again with respect to tide-ice interaction. The tide pattern in the ice-free ocean is presented in the first part of the work. The Arctic Ocean is open to both the Atlantic and Pacific, the non-linear terms in the equations of motion are included, and the space grid step is twice as short as in the previous computations. The shorter step allows greater details, of tide distribution in the adjacent seas to be presented. The inclusion of the White Sea in the model, which is a very strong sink of tidal energy, has caused a significant redistribution of tidal energy in the Barents Sea. The tide in the Barents Sea is studied and the computations are compared with observations and computations presented by Sgibneva (1964). The tide wave pattern in the Arctic Ocean is close to the previous results.

Periodic openings and closings in the pack ice were discovered in calm weather during early voyages to the Arctic by Nansen and Zubov (1955). This phenomenon occurred along the coast of Siberia and in the Greenland Sea but not inside the Arctic Ocean. Legenkov (1958) set up a model to determine ice divergence and convergence from the available observations of tide and current. The first mathematical model of tide motion in the polar seas was built by Kagan (1968), though he did not include internal ice interaction. Kheysin and Ivchenko (1973) developed a model of the periodic oscillation of ice induced by tides, with the interaction between ice floes included. They postulated a viscoelastic model of the ice mechanics and studied the variations of the ice compactness due to the tide in the Sea of Okhotsk. The pattern of ice velocity in time was also computed. A simplified model

Received 13 May 1981.

$\uparrow$ This work was carried out during the author's stay at the Trondheim University, Division of Engineering Cybernetics.

Institute of Meteorology and Water Management, Waszyngtona 42, Gdynia, Poland.

$\S$ Present affiliation, Geophisical Institute, University of Alaska, Fairbanks, Alaska 99701. 
of the ice as a viscous material by Sodhi and Hibler III (1980) showed in a straightforward manner the time lag between water and ice velocities when tide propagates in the ice-covered sea.

One of the most difficult and yet important problems in the study of tides or wind driven motion of the ice is specification of the ice mechanics model. The situation in this field seems to have been accurately described by Rothrock (1975): "we suffer now from too many hypotheses and too few data of sufficient accuracy to test them critically". To represent internal ice interaction we apply the non-linear frictional law proposed by Rothrock (1975). Tide is a phenomenon of a short duration, therefore, the thermodynamical processes of ice growth and decay will be neglected and only ice mechanics will be considered. Though we shall deal with the exact partial differential equations our feeling is that the result of computations from the tide-ice model are to a certain degree of a qualitative nature. Ice mechanics is a new domain which is developing very fast but the lack of experimental knowledge is still acute, see e.g. Pritchard (1980). The empirical coefficients which enter the constitutive law are still not very exact, and the expression proposed by Rothrock (1975) has never been tested against the tide motion. Therefore, part of our effort is directed to the elucidation of the tide-ice interaction under diversified conditions. Because of the non-linear ice mechanics, computations show the existence of a residual ice motion over a tidal period. How important this phenomenon could be in nature is a moot question. The presence of the ice cover leads to the decay of the tide amplitude and to the time lag between the ice and water velocities. It is found that the latter feature depends in a complicated manner on the viscosity parameters of the ice and the water.

2. Basic equations and certain numerical problems related to tide modelling in the Arctic Ocean

The problem of tide in the Arctic region will be studied by a system of equations of motion and continuity written in the stereographic polar coordinate system (Kowalik and Bich Hung 1977);

$$
\begin{gathered}
\frac{\partial M_{x}}{\partial t}+\frac{m M_{x}}{\rho_{w}(H+\zeta)} \frac{\partial M_{x}}{\partial x}+\frac{m M_{y}}{\rho_{w}(H+\zeta)} \frac{\partial M_{x}}{\partial y}-f M_{y} \\
=-m \rho_{w} g(H+\zeta) \frac{\partial \zeta}{\partial x}-\frac{r M_{x}}{(H+\zeta)^{2} \rho_{w}} \sqrt{ }\left(M_{x}{ }^{2}+M_{y}{ }^{2}\right)+m^{2} A \Delta M_{x}+\tau_{\zeta, x} \\
\frac{\partial M_{y}}{\partial t}+\frac{m M_{x}}{\rho_{w}(H+\zeta)} \frac{\partial M_{y}}{\partial x}+\frac{m M_{y}}{\rho_{w}(H+\zeta)} \frac{\partial M_{y}}{\partial y}+f M_{x} \\
=-m \rho_{w} g(H+\zeta) \frac{\partial \zeta}{\partial y}-\frac{r M_{y}}{(H+\zeta)^{2} \rho_{w}} \sqrt{ }\left(M_{x}+M_{y}\right)+m^{2} A \Delta M_{y}+\tau_{\zeta, y} \\
\frac{\partial M_{x}}{\partial x}+\frac{\partial M_{y}}{\partial y}+\rho_{w} \frac{\partial \zeta}{\partial t}=0
\end{gathered}
$$

The ice motion induced by tide will be considered by the following system of equations (Rothrock 1970);

$$
\frac{\partial M I_{x}}{\partial x}-f M I_{y}=-m \rho g H I \frac{\partial \zeta}{\partial x}-\tau_{\zeta, x}+F_{x}
$$




$$
\frac{\partial M I_{y}}{\partial y}+f M I_{x}=-m \rho g H I \frac{\partial \zeta}{\partial y}-\tau_{\zeta, \nu}+F_{y}
$$

In the above equations;

$x, y$ are horizontal coordinates, with $x$ and $y$ directed along $0^{\circ}$ and $90^{\circ} \mathrm{E}$ longitude, and with origin at the North Pole. In all expressions where $x$ or $y$ are subscripts, they denote the components of a vector and are directed along the $x$ and $y$ axes, respectively;

$M_{x}, M_{y}$ are the components of the water mass transport vector $\boldsymbol{M}$;

$M I_{x}, M I_{y}$ are the components of the ice mass transport vector $M I$;

$\tau_{\zeta, x}, \tau_{\zeta, y}$ are the components of the water stress vector $\tau$;

$F_{x}, F_{y}$ are the components of the internal ice force $F$;

$\zeta$ is the elevation of water surface or ice surface above the undisturbed level.

$\Delta=\frac{\partial^{2}}{\partial x^{2}}+\frac{\partial^{2}}{\partial y^{2}}=$ Laplace operator

$H=$ water depth;

$r=$ bottom stress coefficient having a constant value of $3 \times 10^{-3}$;

$A=$ lateral eddy viscosity (kinematic) coefficient taken as $5 \times 10^{8} \mathrm{~cm}^{2} / \mathrm{s}$;

$f=$ Coriolis parameter;

$g=$ gravity acceleration;

$\rho_{w}=$ water density taken as $1 \mathrm{~g} / \mathrm{cm}^{3}$;

$m=$ scale factor relating a stereographic map to a sphere;

$\rho=$ ice density, equal to $0.9 \mathrm{~g} / \mathrm{cm}^{3}$;

$H I=$ thickness of the ice.

The interaction between the ice and the water is expressed in the above equations, by means of: (A) the water stress $\tau$, which depends on the relative motion of the ice and the water, and (B) the horizontal gradient of pressure arising due to the sea slope. The latter term is completely defined, but the former contains a coefficient which is a function of the aerodynamical properties of the ice-water surface.

To derive the solution to the above system the pertinent boundary and initial conditions should be added. Among all possible sets of boundary conditions the chosen one should lead to the unique solution of the system (1-5). Such a set of conditions is still undefined for the ice-ocean interaction, therefore, we shall assume, (since the ice flow equations are analogous to the water flow equations), that specification of the normal and the tangential mass transports along the boundaries is sufficient to derive the unique solution-Marchuk et al. (1972). Throughout the observations, on the open boundaries, North Scandinavia-Greenland and Bering Strait, only sea level is defined. To comply with the above requirement of uniqueness the system of eqns. (1-5) is simplified on the open boundaries in such a way that the value of sea level is sufficient to derive the unique solution, see Kowalik and Untersteiner (1978).

When searching for the numerical solution of the tide-ice interaction in the Arctic Ocean the scheme of Hansen (1962), which is explicit in time and staggered 
in space, is applied. All three variables are set apart; the shortest distance between the grid points $(h)$ is equal to $37.5 \mathrm{~km}$ and the time step $(T)$ is $62.1 \mathrm{~s}$. The basic framework for computing the $\mathrm{M}_{2}$ tide in the Arctic Ocean was designed by Kowalik and Untersteiner (1978), therefore, we shall not discuss all the numerical problems but only the new ones arising from the considerations of both water and ice in one model.

In the equations of motion (1), (2) the non-linear advective terms, which were not included previously, are considered. The numerical approximation of these terms is due to Tee (1976). Generally the non-linear effects are small, therefore the condition for numerical stability is not modified by this term.

The presence of ice does not influence the principal stability condition of the explicit numerical scheme (Ramming and Kowalik 1980);

$$
T \leqslant \frac{h}{m \sqrt{ } 2 g H},
$$

because the replacement of the water depth $(H)$ in $(6)$ by the ice thickness $(H I)$, could change the inequality only in the case of $H I>H$.

The significant difficulty of preserving numerical stability of the explicit numerical scheme is due mainly to the processes of internal friction, expressed by the lateral exchange of momentum. Internal ice friction terms, to be considered later on, contain expressions similar to the lateral exchange of momentum in eqns. (1) and (2). The ice (kinematical) viscosity coefficient, an analogue of kinematical eddy viscosity of water, takes quite high values up to $10^{12} \mathrm{~cm}^{2} / \mathrm{s}$. Therefore, the question arises: how does the stability condition depend on the magnitude of the horizontal viscosity?

A practical solution of this problem is to apply a series of values of the eddy viscosity $A$ from a range of $10^{6}-10^{12} \mathrm{~cm}^{2} / \mathrm{s}$ and to compute the tide distribution in the ice-free ocean. Setting initial values to zero, the sea level is then calculated throughout 10 tidal periods in the whole Arctic. The results in Fig. 1 depict sea level variations in the Barents Sea for the two values of eddy viscosity $A=10^{7} \mathrm{~cm}^{2} / \mathrm{s}$ and $A=5 \times 10^{8} \mathrm{~cm}^{2} / \mathrm{s}$. The level computed with $A=10^{7} \mathrm{~cm}^{2} / \mathrm{s}$ does not reach the periodical oscillation even after 10 tidal periods from the beginning of simulation; the situation is quite different when $A=5 \times 10^{8} \mathrm{~cm}^{2} / \mathrm{s}$. Over the range of $10^{8} \mathrm{~cm}^{2} / \mathrm{s}$ $<A<10^{12} \mathrm{~cm}^{2} / \mathrm{s}$ the numerical scheme is stable, but if $A$ is increased above $10^{12} \mathrm{~cm}^{2} / \mathrm{s}$ the scheme is again unstable. The general condition (6), under such circumstances, should be assisted by the condition related to the frictional forces (Kowalik and Untersteiner 1978);

$$
T \leqslant\left(r_{1}+2 m^{2} \frac{A}{h^{2}}\right) / 2 f^{2}
$$

The bottom friction coefficient $r_{1}=\left[r / \rho_{w}(H+\zeta)^{2}\right] \sqrt{ }\left(M_{x}{ }^{2}+M_{y}{ }^{2}\right)$ in the deep ocean $(H \rightarrow \infty)$ can be neglected. This gives us the opportunity of observing the dependence of stability condition on the horizontal friction only. When the magnitude of $A$ defined by the exchange of momentum in the oceanic turbulent processes is put into (7), the time step $T$ is greater than the time step derived by (6). On the other hand, when $A$ falls below a certain limit the time step defined by (7) may be shorter than the time step calculated by (6). Therefore the choice of time step through (6) may lead to instability-see fig. 1 . 


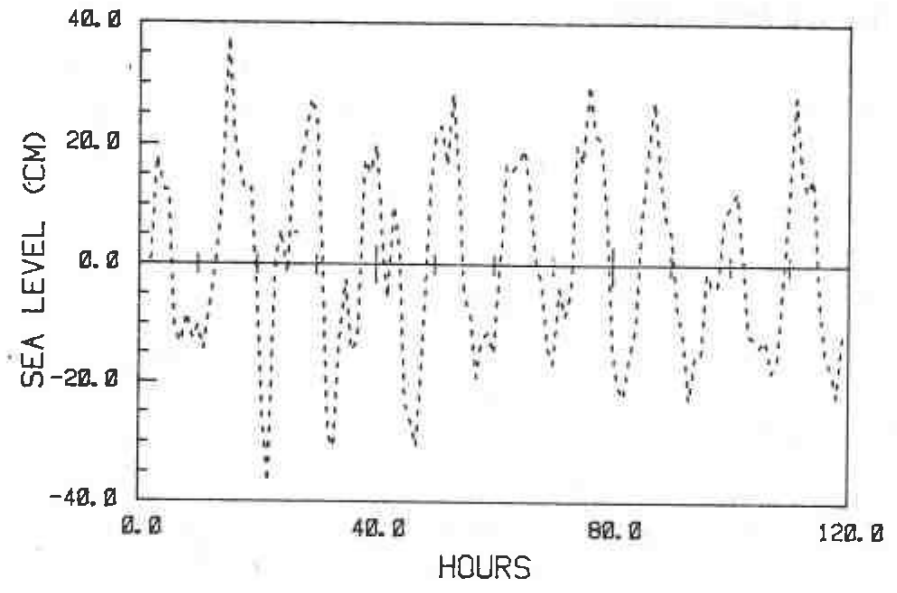

$\ldots A=1 . \square E 7$

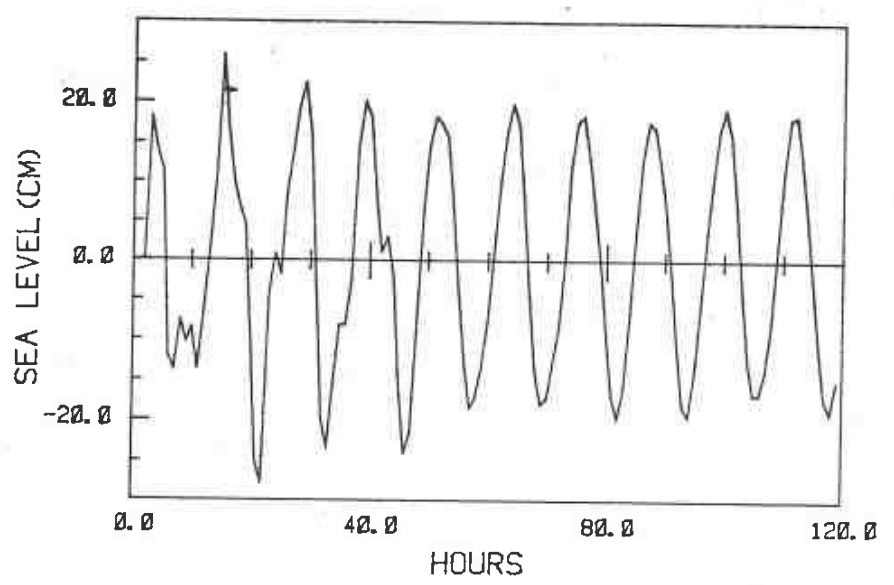

- $A=5$. DEB

Figure 1. Tide amplitude computed during 10 tidal periods in the Barents Sea (position $74^{\circ} \mathrm{N}, 34^{\circ} \mathrm{E}$ ). Upper part-eddy viscosity $A=10^{7} \mathrm{~cm}^{2} / \mathrm{s}$, lower part-eddy $A=5 \times 10^{8}$ $\mathrm{cm}^{2} / \mathrm{s}$.

The horizontal eddy viscosity also enters into the condition which defines the stability in the short wave domain (Kagan 1970);

$$
T \leqslant 1 /\left(r_{1}{ }^{2}+m^{2} 2 A / h^{2}\right)
$$

Considering again the deep ocean case, when $r_{1} \approx 0$, and taking into account both (7) and (8), the range of variations of the horizontal viscosity is defined;

$$
T\left(\frac{f h}{m}\right)^{2} \leqslant A \leqslant \frac{1}{2 T}\left(\frac{h}{m}\right)^{2}
$$

Taking the values which will be applied in computations of $\mathrm{M}_{2}$ tide in the Arctic Ocean; $h=37.5 \mathrm{~km}, T=62 \cdot 1 \mathrm{~s}, f=1.4 \times 10^{-4} \mathrm{~s}^{-1}, m \approx 0.9$; the range of $A$ for the stable computation is found from $2 \cdot 1 \times 10^{7} \mathrm{~cm}^{2} / \mathrm{s}$ to $1.4 \times 10^{11} \mathrm{~cm}^{2} / \mathrm{s}$. 


\section{Tides in the ice-free ocean}

To derive the solution of system (1-3), the no-slip condition is specified at the coast. On the open boundary between Northern Norway and Central Greenland, the sea level is specified by Kowalik and Untersteiner (1978), and in the Bering Strait by Sündermann (1970). Co-tidal and co-range lines derived from the numerical computations are plotted in Fig. 2 and Fig. 3. The phase angle is referred to Greenwich and is expressed in degrees. In Fig. 4 the velocity along the major axis together with direction of rotation along the ellipse is given. Figure 5, which is complementary to Fig. 4, depicts boundaries between positive (counterclockwise) and negative (clockwise) directions of rotations. Knowledge of directions of rotation in tide ellipse may help to discriminate between tidal and inertial oscillations, because their periods in the Arctic Ocean are often very close (Hunkins 1967).

The $\mathrm{M}_{2}$-tide entering the Arctic Ocean between Greenland and Scandinavia is divided by Spitsbergen into two branches. The main wave enters through the Greenland Sea and the secondary wave propagates around Scandinavia towards the White Sea. The results in the Arctic Ocean follow the same general pattern

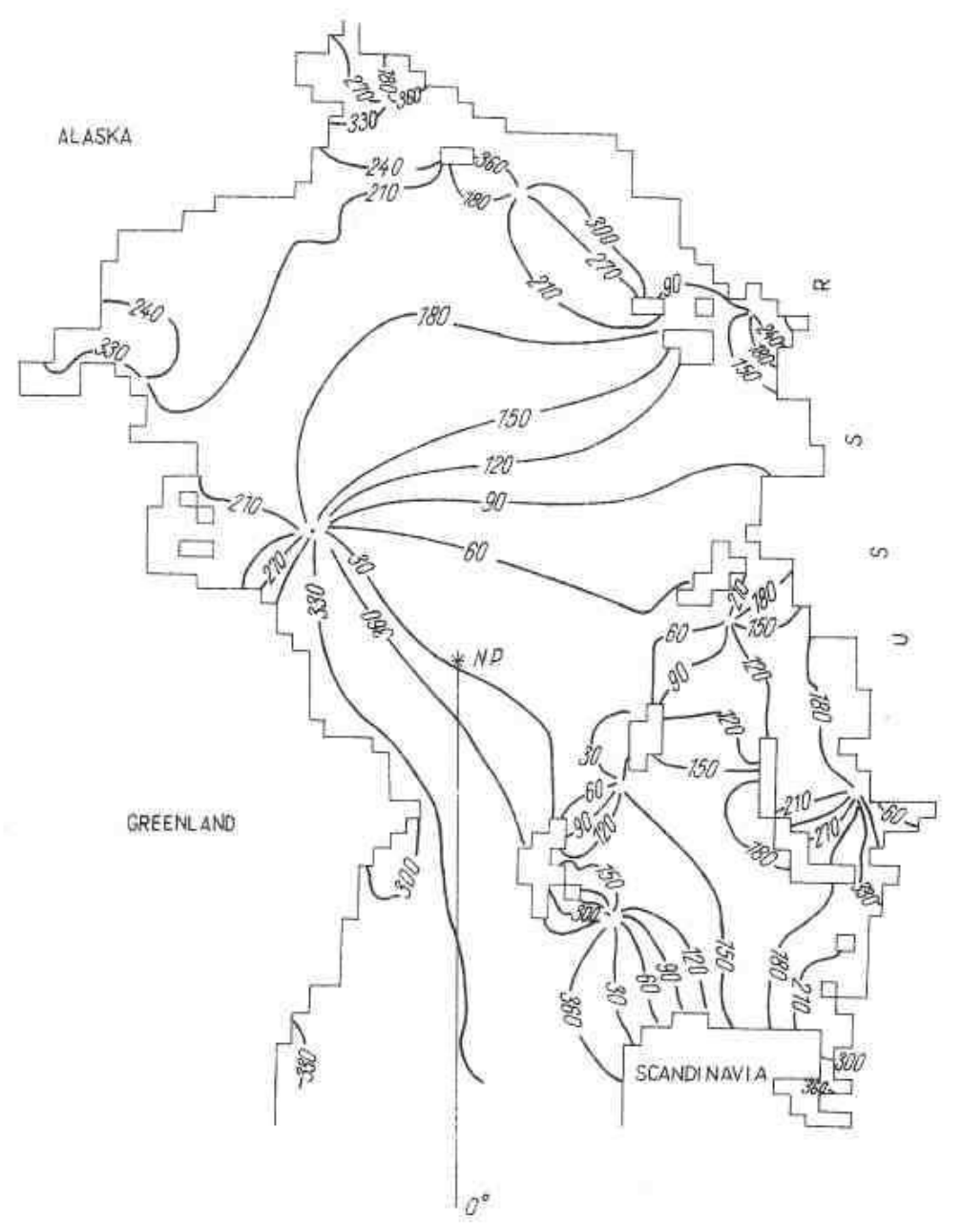

Figure 2. Co-tidal lines of the $\mathbf{M}_{2}$ tide in the ice-free Arctic Ocean. Phase angles in degrees are referred to Greenwich (solar time). 


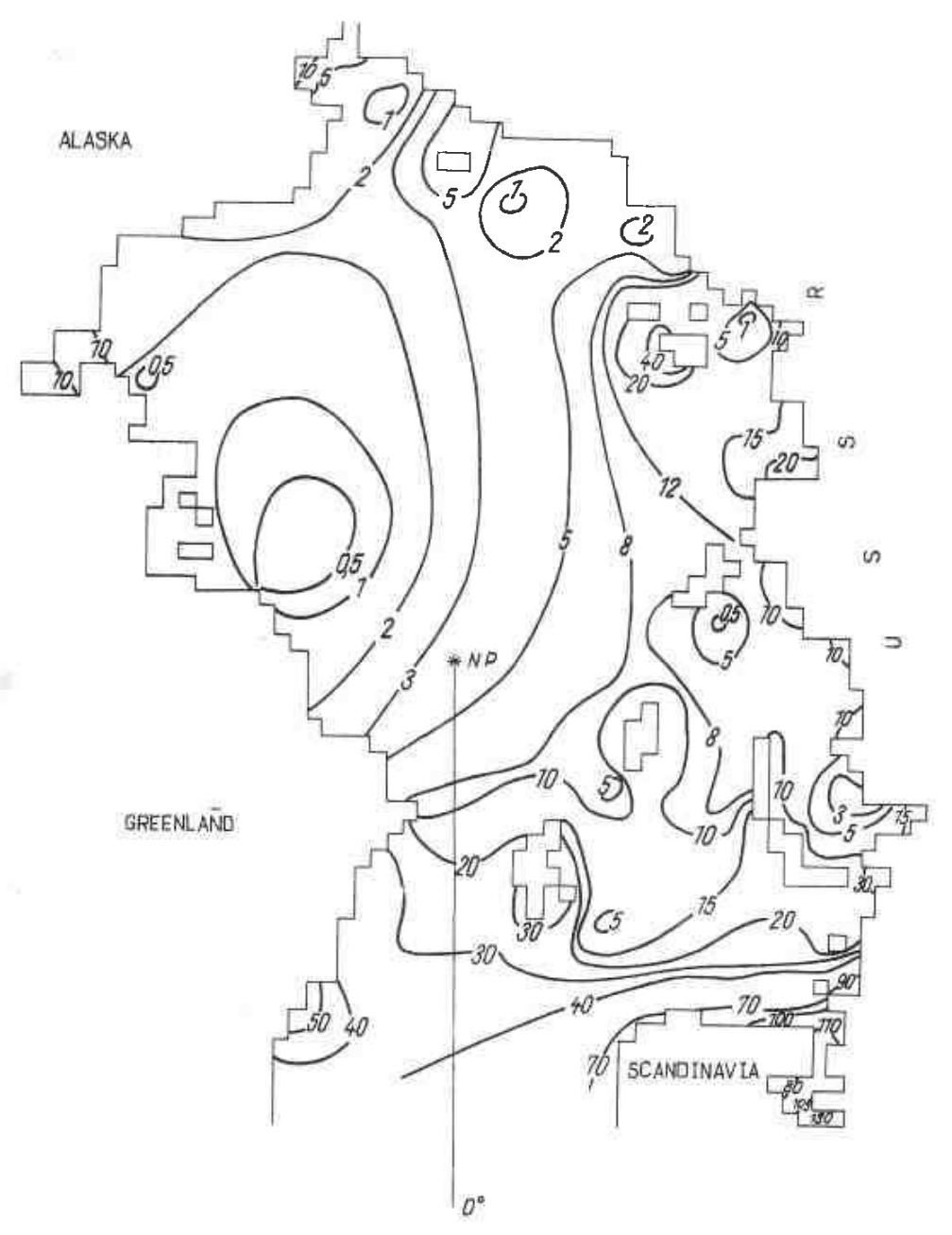

Figure 3. Co-range lines of the $\mathbf{M}_{\mathbf{2}}$ tide in the ice-free Arctic Ocean, amplitudes in $\mathrm{cm}$.

described by Kowalik and Untersteiner (1978). The tidal wave travels around the amphidromic point off North Canada. In the adjacent seas the present picture is more detailed. On the North Siberian Shelf in the East Siberian Sea and Laptev Sea, the amphidromic points are clearly seen. This proves that not only dissipation processes occurring over the North Siberian Shelf (Kowalik 1979), but also energy scattering processes play a significant role in tide propagation. The details discerned in the present computations are due to the improved space resolution. Comparing the present results with Kowalik and Untersteiner (1978) it is seen that the amplitude is now somewhat smaller. The White Sea is taken into account in the present computation, therefore the tide entering this sea is dissipated to a great extent, and this in turn influences the amplitude distribution in the whole Arctic. The tide pattern in the Arctic Ocean was analysed by Kowalik and Untersteiner (1978), the ncw results provide an opportunity to study the tide propagation in the Barents Sea. From Fig. 2 and Fig. 3 it is observed that the tide wave propagates around Scandinavia and enters into the shallow and narrow White Sea, where it attains (by our calculation) an amplitude of $2 \mathrm{~m}$. Not all the energy is directed towards the White Sea; part of the wave being reflected back toward the Atlantic Ocean; the other 


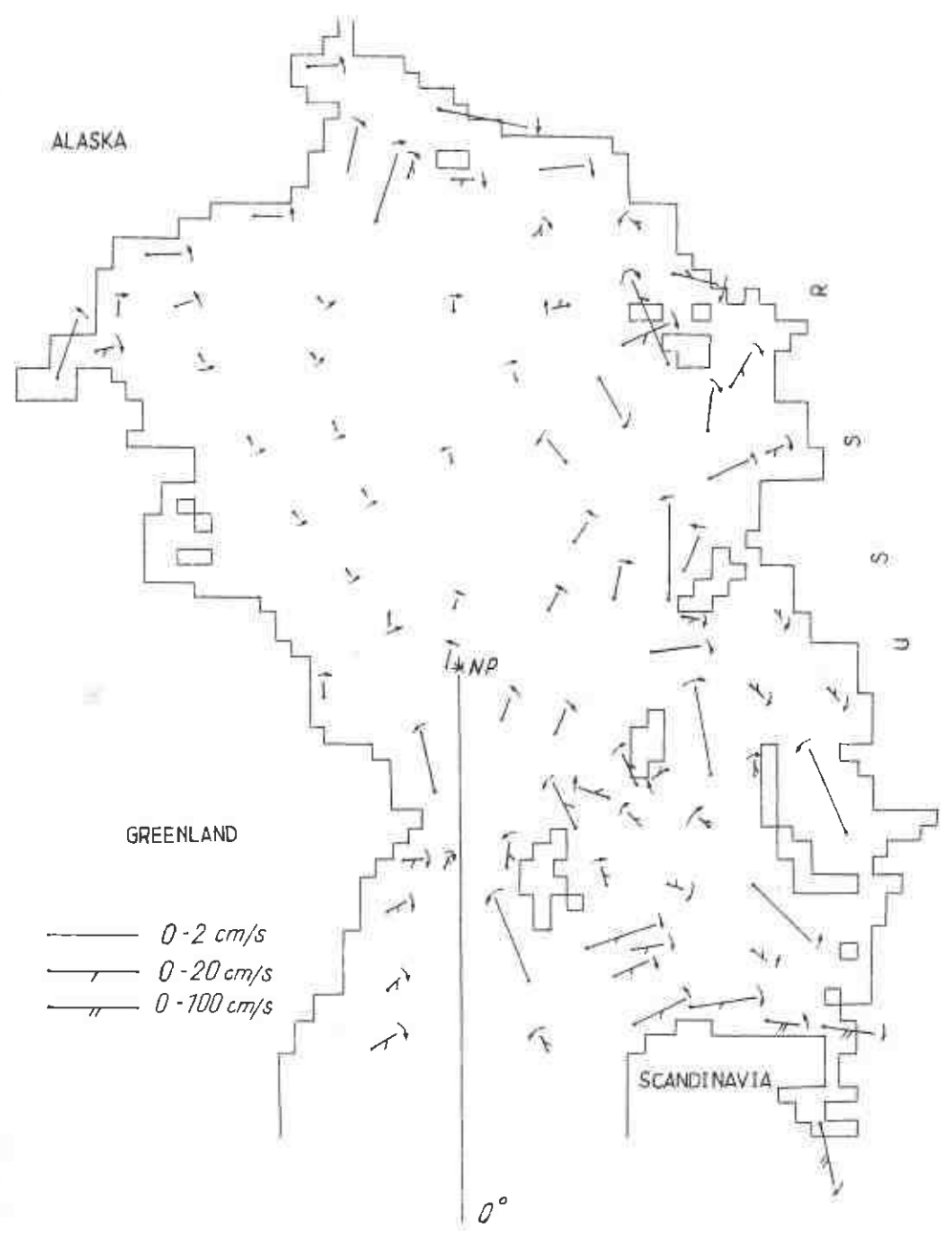

Figure 4. Major axis of the $M_{2}$ tide ellipse in the ice-free Arctic Ocean. Arrows indicate the direction of rotation along ellipses.

branch propagates toward the North. Superposition of the reflected and incident waves forms an amphidromic point (Taylor 1921). In the Barents Sea two distinct amphidromic points and a decayed one (off the coast of Novaya Zemlya) are observed. The first is situated between Spitsbergen and North Cape and the second between Spitsbergen and Franz Josef Land. Both amphidromic points are shifted from the geographically mean position. The shift is related to the amplitudes of the forward and backward Kelvin waves. The dislocation always takes place towards the coast where the tidal amplitude is smaller, see e.g. Nekrasov (1975), Kowalik (1979).

Sgibneva (1964) compiled data relating to the $M_{2}$ wave in the Barents Sea. Basing on a simplified set of equations she also computed the phase and amplitude distribution. To compare both results, Fig. 6 contains the co-tidal lines from Sgibneva (1964) - continuous line, and computed by means of the set of eqns. (1-3) dash line. The locations of the amphidromical points are quite close and also good phase resemblance is observed along the Scandinavian Coast. Somewhat unusual is the clockwise rotation around the amphidromic point between Spitsbergen and Franz Josef Land in Sgibneva's (1964) results. 


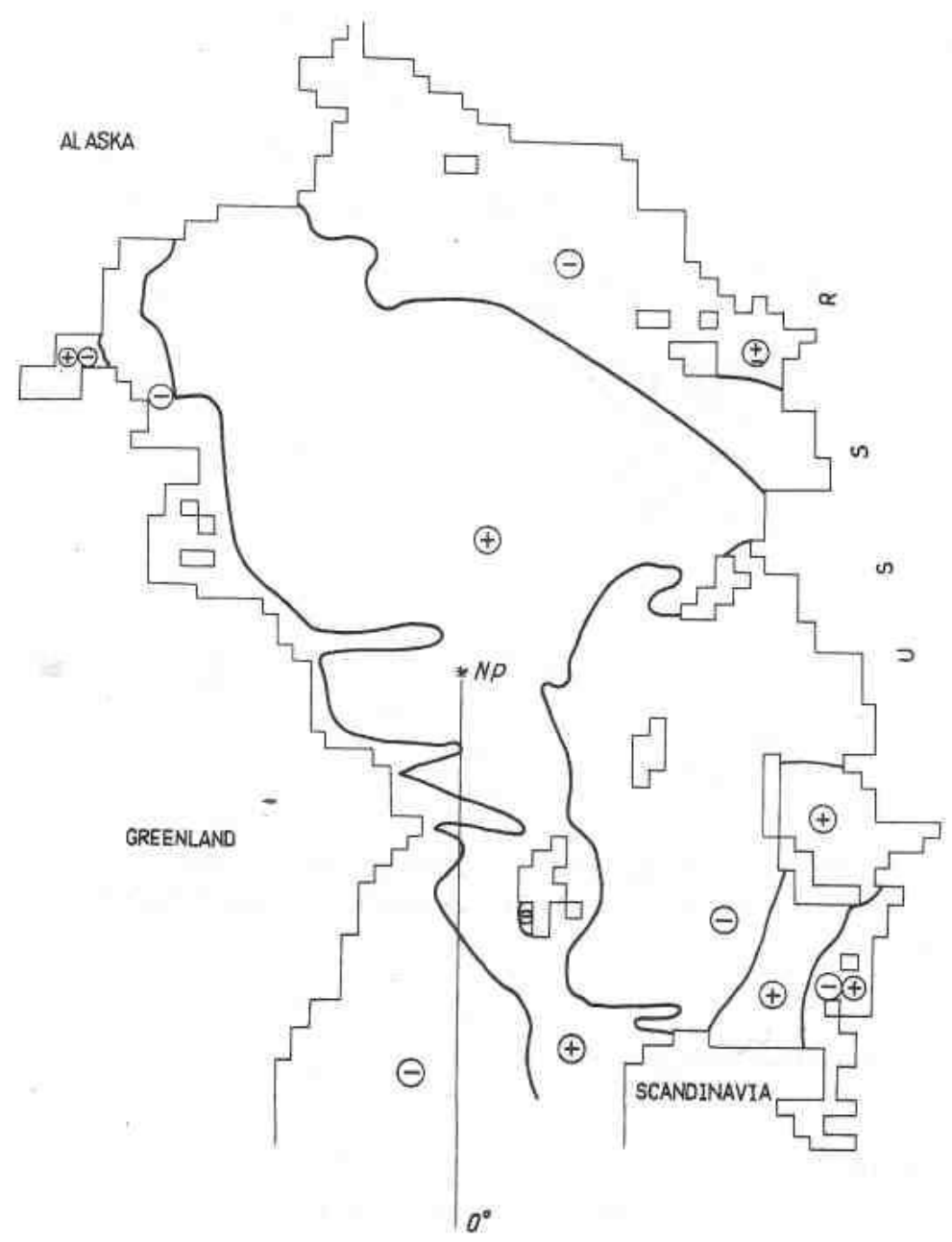

Figure 5. Direction of rotation along the tidal ellipse. Plus denotes counter-clockwise direction and minus clockwise direction.

In Table 1 computed $\mathrm{M}_{2}$ tides are compared against the observed values at several points around the Barents Sea. Gauge data are taken from tables published by the International Hydrographic Bureau in Monaco. The best agreement between the computations and the measurements is around Scandinavian coasts. The overall comparison clearly shows that the computed amplitude and phase are smaller than the measured values. The complicated geometry around islands cannot be adequately described by the grid mesh of $37.5 \mathrm{~km}$. Because the observations are usually taken from the tide gauges situated in narrow bays or close to the coast, the result of the computations can be improved by improvement of the horizontal resolution.

\section{Tide-ice interaction}

Equations (4) and (5) express the lateral motion of the ice by means of the mass transport, if the ice has velocity $u$ and $v$ along $x$ and $y$ coordinates, respectively, and thickness $H I$, then,

$$
M I_{x}=\int_{0}^{H I} \rho u d z ; \quad M I_{y}=\int_{0}^{H I} \rho v d z
$$




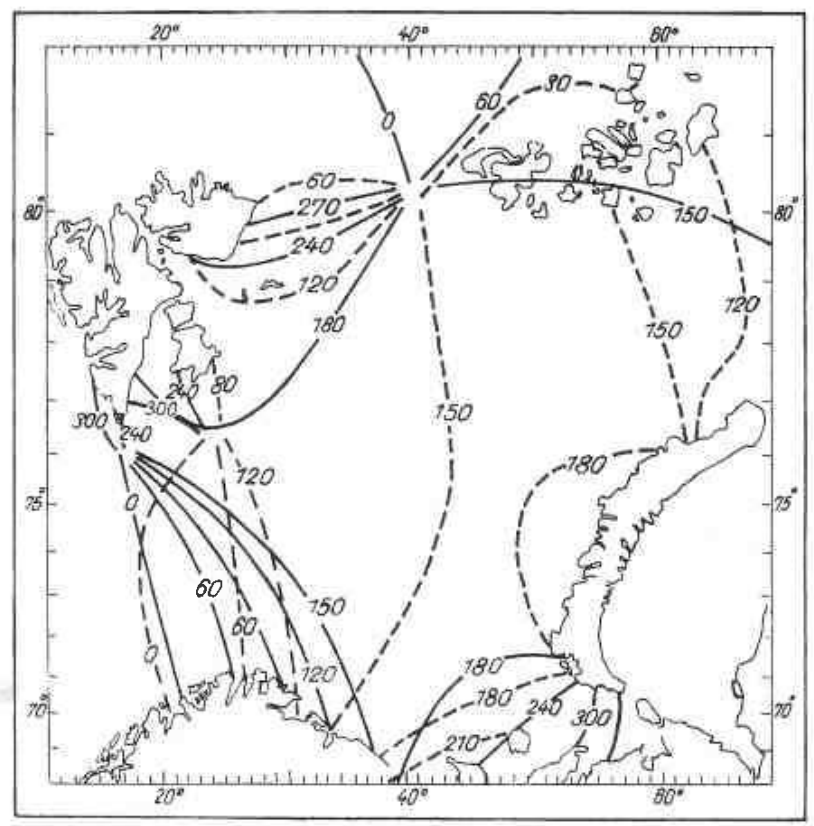

Figure 6. Cotidal lines of the $\mathrm{M}_{2}$ tide in the ice-free Barents Sea. Continuous line, according to Sgibneva (1964); dotted line, present model.

\begin{tabular}{|c|c|c|c|c|}
\hline \multirow{2}{*}{ Location } & \multicolumn{2}{|c|}{ Amplitude $(\mathrm{cm})$} & \multicolumn{2}{|c|}{ Phase } \\
\hline & Observed & Calculated & Observed & Calculated \\
\hline \multicolumn{5}{|l|}{ Scandinavia } \\
\hline $69^{\circ} 38 \cdot 8^{\prime} \mathrm{N}, 18^{\circ} 52^{\prime} \mathrm{E}$ & $87 \cdot 6$ & 76 & $39^{\circ}$ & $26^{\circ}$ \\
\hline $69^{\circ} 55^{\prime} \mathrm{N}, \quad 32^{\circ} 02^{\prime} \mathrm{E}$ & $99 \cdot 1$ & 77 & $151^{\circ}$ & $140^{\circ}$ \\
\hline $69^{\circ} 05^{\prime} \mathrm{N}, \quad 36^{\circ} 18^{\prime} \mathrm{E}$ & $130 \cdot 8$ & 102 & $220^{\circ}$ & $180^{\circ}$ \\
\hline \multicolumn{5}{|l|}{ Novaya Zemlya } \\
\hline $76^{\circ} 56^{\prime} \mathrm{N}, \quad 68^{\circ} 58^{\prime} \mathrm{E}$ & 15 & 9 & $323^{\circ}$ & $125^{\circ}$ \\
\hline $76^{\circ} 16^{\prime} \mathrm{N}, \quad 63^{\circ} 03^{\prime} \mathrm{E}$ & $15 \cdot 2$ & 9 & $283^{\circ}$ & $150^{\circ}$ \\
\hline \multicolumn{5}{|l|}{ Franz Josef Land } \\
\hline $81^{\circ} 48^{\prime} \mathrm{N}, \quad 57^{\circ} 51^{\prime} \mathrm{E}$ & $16 \cdot 6$ & 12 & $182^{\circ}$ & $50^{\circ}$ \\
\hline $80^{\circ} 20^{\prime} \mathrm{N}, \quad 52^{\circ} 48^{\prime} \mathrm{E}$ & $9 \cdot 3$ & 14 & $262^{\circ}$ & $160^{\circ}$ \\
\hline \multicolumn{5}{|l|}{ Spitsbergen } \\
\hline $79^{\circ} 56^{\prime} \mathrm{N}, \quad 18^{\circ} 18^{\prime} \mathrm{E}$ & $28 \cdot 1$ & 19 & $114^{\circ}$ & $16^{\circ}$ \\
\hline $78^{\circ} 13^{\prime} \mathrm{N}, \quad 15^{\circ} 38^{\prime} \mathrm{E}$ & $48 \cdot 1$ & 24 & $33^{\circ}$ & $355^{\circ}$ \\
\hline \multicolumn{5}{|l|}{ Bjørnøya } \\
\hline $74^{\circ} 29^{\prime} \mathrm{N}, \quad 19^{\circ} 12^{\prime} \mathrm{E}$ & $34 \cdot 2$ & 28 & $42^{\circ}$ & $5^{\circ}$ \\
\hline
\end{tabular}

Table 1. Observed and computed amplitudes and phase angles of the $\mathrm{M}_{2}$ tide in the Arctic Ocean. 
Assuming the ice is not spread evenly over the whole surface the compactness $(N)$ can be inserted into the above expression;

$$
M I_{x}=\rho N u H I ; \quad M I_{y}=\rho N v H I
$$

The expression $\rho N H I$ denotes concentration or mass per unit area; in the computation to follow $\rho N H I$ is equal to $200 \mathrm{~g} / \mathrm{cm}^{2}$.

Any interaction between the water and the ice in the system of eqns. (1-5), is described by two forces, i.e. the pressure gradient and the water stress. The former is fully defined if the sea level distribution is given over the sea, the latter we take as,

$$
\begin{gathered}
\tau_{\zeta, x}=R\left(u-u_{w}\right)\left[\left(u-u_{w}\right)^{2}+\left(v-v_{w}\right)^{2}\right]^{1 / 2} \\
\tau_{\zeta, y}=R\left(v-v_{w}\right)\left[\left(u-u_{w}\right)^{2}+\left(v-v_{w}\right)^{2}\right]^{1 / 2}
\end{gathered}
$$

Here $u_{w}$ and $v_{w}$ are the components of the water velocity vector.

Water stress is sensitive both to the relative motion of the water and the ice, and to the magnitude of the-coefficient $R$. The water drag coefficient is a function of the aerodynamic properties of the ice-water interface and the relative motion, its magnitude range from $3 \times 10^{-3}$ to $5 \cdot 5 \times 10^{-3}$.

For the pack ice drift in summer due to wind, McPhee (1980) estimated the water drag magnitude to be from $4 \times 10^{-3}$ to $5 \cdot 5 \times 10^{-3}$. Tide-ice interaction occurs permanently, while the ice cover changes seasonally due to growth and decay. During winter, with the thick ice cover over the ocean, the drag coefficient may diminish to $3 \times 10^{-3}$ which is characteristic of the flow regime over the bottom. Also our computations will be performed with $R=3 \times 10^{-3}$, and we shall indicate the influence of the variable drag coefficient on the overall picture of the tide-ice interaction.

The main problem to be clarified before the water-ice interaction can be studied is the formulation of a constitutive law which relates the stress $(\sigma)$ transmitted between floes to the variables in the problem formulated by the system $(1-5)$. The mechanism of ice interaction in the simplest case can be expressed by a linear viscous model, when the ice stress is proportional to strain rate tensor-Glen (1970), Campbell (1965). Sophisticated models of the internal interaction, when the ice thickness is related to the ice strength and the pack ice is treated as elastic-plastic or non-linear viscous material, were proposed by Coon et al. (1974) and Hibler III (1979). Treatment of pack ice as an elastic-plastic material, even in the case of the very simple constitutive law proposed by Kheysin and Ivchenko (1973), brings into consideration additional variables, not specified in the system (1-5). In the present work the nonlinear viscous constitutive law proposed by Rothrock (1975) will be taken into account because it contains the variables specified in the equations of motion. The mechanical behaviour of ice is considered only; we shall assume that during 12 hours the ice thickness can be regarded as constant and thermodynamic processes, neglected. The force $\boldsymbol{F}$ in eqns. (4) and (5) acting on the ice floes due to the internal ice stresses is given by the divergence of the stress tensor $\left(\sigma_{i j}\right)$;

$$
F_{i}=\frac{\partial \sigma_{t j}}{\partial x_{j}} \rho N H I
$$


The stress-strain relationship is defined as follows;

$$
\sigma_{i j}=2 \eta \dot{\epsilon}_{i j}+(\lambda-\eta) \dot{\epsilon}_{k k} \delta_{i j}-p \delta_{i j}
$$

Here $i, j$ are indices; they take the value 1 or 2 , where 1 stands for the $x$ coordinate, 2 stands for the $y$ coordinate. The strain-rate in (14) is expressed by the ice velocity as,

$$
\dot{\epsilon}_{i j}=\frac{1}{2}\left(\frac{\partial u_{i}}{\partial x_{j}}+\frac{\partial u_{j}}{\partial x_{i}}\right)
$$

Rothrock (1975) suggested that the tensile stress is negligible compared to compressive stresses, with component $(p)$ in (14) given by;

$$
\left.\begin{array}{ll}
p=-A P \frac{\partial u_{i}}{\partial x_{i},} & \text { when } \frac{\partial u_{i}}{\partial x_{i}}<0 \\
p=0, & \text { when } \frac{\partial u_{i}}{\partial x_{i}} \geqslant 0
\end{array}\right\}
$$

Finally, introducing (14), (15) and (16) into (13) the components $F_{x}$ and $F_{y}$ of the force due to the internal ice stress are derived;

$$
\begin{aligned}
& F_{x}=\left[\eta \Delta u+\lambda \frac{\partial}{\partial x}\left(\frac{\partial u}{\partial x}+\frac{\partial v}{\partial y}\right)-\frac{\partial p}{\partial x}\right] \rho N H I \\
& F_{y}=\left[\eta \Delta v+\lambda \frac{\partial}{\partial y}\left(\frac{\partial u}{\partial x}+\frac{\partial v}{\partial y}\right)-\frac{\partial p}{\partial y}\right] \rho N H I
\end{aligned}
$$

In the ensuing computations both bulk $(\lambda)$ and shear $(\eta)$ viscosity coefficients are taken to be equal $\lambda=\eta=A I$. The ice velocity components in the above expressions are denoted by $u$ and $v$ or by $u_{1}$ and $u_{2}$. Throughout all indexed expressions the Einstein summation convention is used. The constituent law has never been tested against tide propagation in an ice-covered ocean. In this law at least two empirical constants, which express the mechanism of floe interaction, are unknown, i.e. the coefficient of viscosity $(A I)$ and the pressure coefficient $(A P)$. The magnitude of the viscosity coefficients is quite difficult to estimate. In the case of mean ice drift in the Arctic Basin or in the Weddell Sea, Campbell (1965), Ling et al. (1980) found the coefficients by tuning the computed pattern of circulation to the observed one.

The coefficient of viscosity, being a function of ice strength, changes from values which are close to the water eddy viscosity-during the summer period-when pack ice is loose and the floe interaction is practically negligible, up to large valuesduring winter-when ice motion is stopped completely due to the thermodynamic processes of ice growth.

The compressive non-linear stress incorporated into the equation of state (14), and which relates the pressure $(p)$ of the ice to its convergence, should eventually lead in the case of convergence to suppressing ice motion. Therefore, the magnitude of the pressure coefficient $A P$ in (16) will be defined over the range of the largest $A I$. To find the value of the ice viscosity coefficient $(A I)$ responsible for suppressing the ice motion we start our computations with the linear viscous model $(p=0)$. A sequence of investigations was carried out in the Arctic Ocean with the set of eqns. (1-5) to evaluate the influence of variations of $A I$ on the behaviour of the system. AI ranged from $10^{9} \mathrm{~cm}^{2} / \mathrm{s}$ to $10^{11} \mathrm{~cm}^{2} / \mathrm{s}$, the other parameters were fixed: $\rho N H I=200 \mathrm{~g} / \mathrm{cm}^{2}, R=3 \times 10^{-3}, A=5 \times 10^{8} \mathrm{~cm}^{2} / \mathrm{s}$. The ice and water velocities 


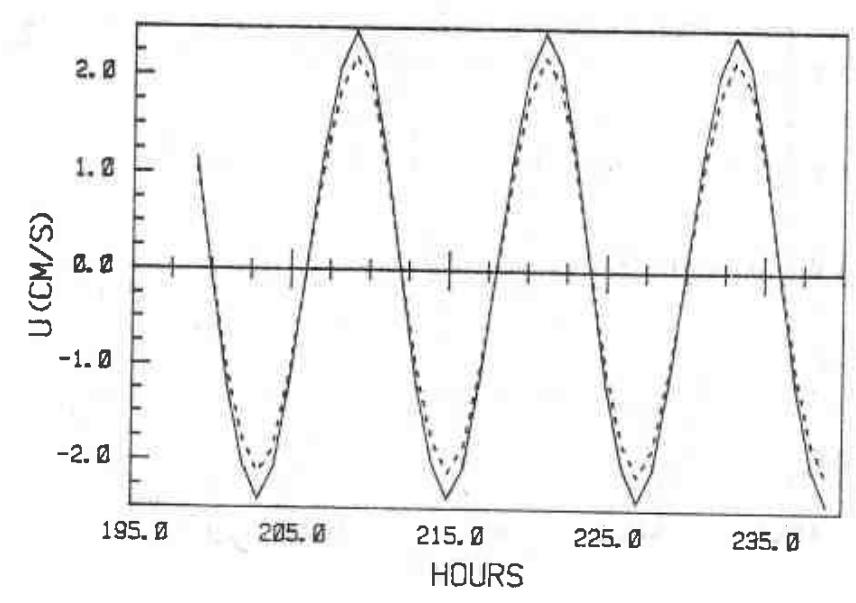

$A[=1$. QE 9

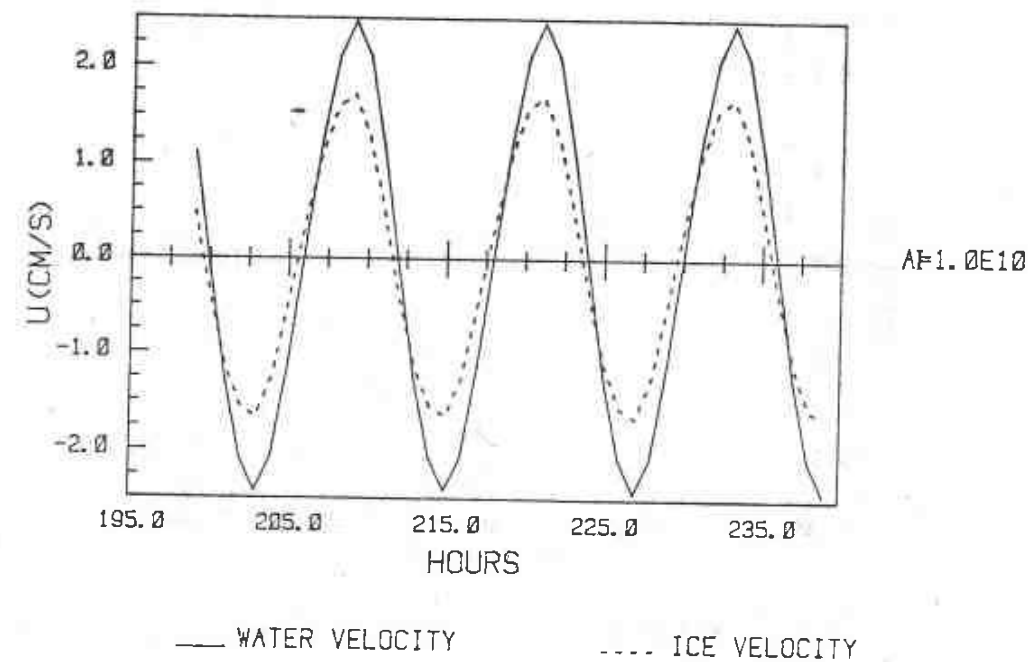

Figure $7(a)$. Water and ice velocity in the Barents Sea (position $74^{\circ} \mathrm{N}, 34^{\circ} \mathrm{E}$ ), computed using the linear viscous model of the ice floe interaction. Eddy viscosity of water $A=5 \times 10^{8} \mathrm{~cm}^{2} / \mathrm{s}$, ice friction coefficient, $A I=10^{9} \mathrm{~cm}^{2} / \mathrm{s}$ (upper part), $A I=10^{10}$ $\mathrm{cm}^{2} / \mathrm{s}$ (lower part), water drag coefficient $R=3 \times 10^{-3}$.

(along the $x$-axis) at an internal point of the Barents Sea $\left(74^{\circ} \mathrm{N}, 34^{\circ} \mathrm{E}\right)$ are plotted in Fig. $7(a)$ and $7(b)$. If the value of $A I$ is close to the magnitude of the horizontal eddy viscosity $A$, the ice and the water velocities are of the same order; when $A I$ increases, noticeable differences can be seen if water and ice velocities are compared. Finally when the friction coefficient growth as high as $10^{11} \mathrm{~cm}^{2} / \mathrm{s}$, the ice velocity is suppressed down to $0 \cdot 1 \mathrm{~cm} / \mathrm{s}$. Two phenomena can be seen in the results of the computations, i.e. the decay of the ice velocity and the time lag between the water and the ice velocities.

The observed time lag between the velocities is dependent on the ice viscosity coefficient but the dependence is more complicated than the one postulated by Sodhi and Hibler III (1980). The lag is close to zero if $A I$ is close to $A$, but the same situation is observed for the very large $A I$-see Fig. 8 . This shows that the lag is a 

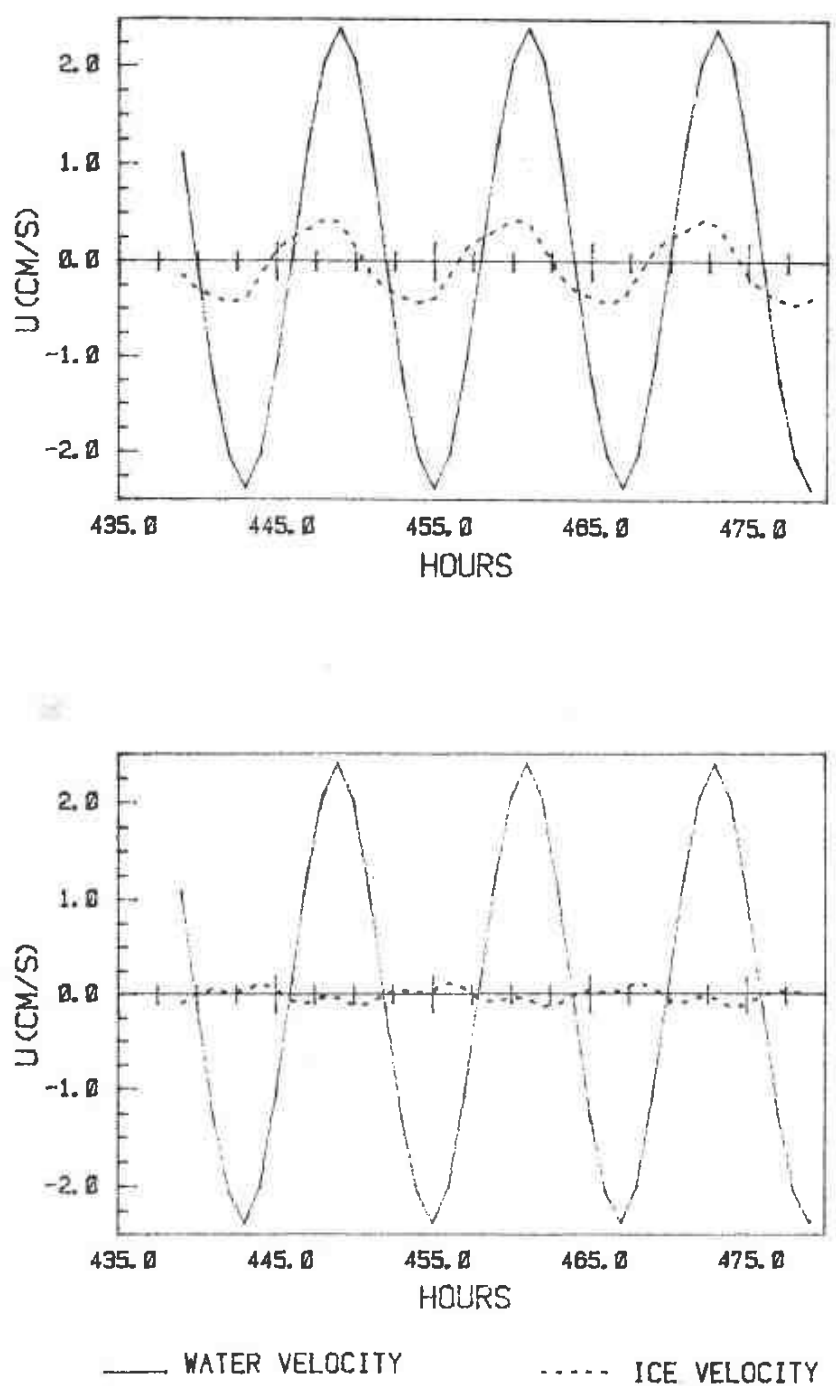

Figure $7(b)$. Water and ice velocity in the Barents Sea (position $74^{\circ} \mathrm{N}, 34^{\circ} \mathrm{E}$ ), computed using the linear viscous model of ice floe interaction. Eddy viscosity of water $A=5 \times 10^{8} \mathrm{~cm}^{2} / \mathrm{s}$, ice friction coefficient, $A I=5 \times 10^{10} \mathrm{~cm}^{2} / \mathrm{s}$ (upper part), $A I=10^{11}$ $\mathrm{cm}^{2} / \mathrm{s}$ (lower part), water drag coefficient $R=3 \times 10^{-3}$.

complicated function of the internal ice stress and attains the largest values when $A I$ is somewhere inside range $10^{9}-10^{11} \mathrm{~cm}^{2} / \mathrm{s}$.

Friction through the viscous stresses suppresses the ice oscillations and when the ice friction coefficient attains a high enough value, the ice motion is stopped, but this phenomenon also depends on the energy transport from tide to ice oscillation. To describe the role of the water stress in the energy transport process the magnitude of the water drag coefficient $3 \times 10^{-3}$ in expression (12) was replaced by $5.5 \times 10^{-3}$, and a set of experiments over the previous range of $A I$ was carried out. The higher water drag coefficient has a definite impact-the motion is not suppressed even when $A I=10^{11} \mathrm{~cm}^{2} / \mathrm{s}$-Fig. 8 ; this feature occurs if the coefficient is increased to $10^{12} \mathrm{~cm}^{2} / \mathrm{s}$.

Finally, we can return to the pressure term in (14), and it stems from the above experiments that the pressure coefficient $A P$ ranges from $10^{11} \mathrm{~cm}^{2} / \mathrm{s}$ to $10^{12} \mathrm{~cm}^{2} / \mathrm{s}$. 

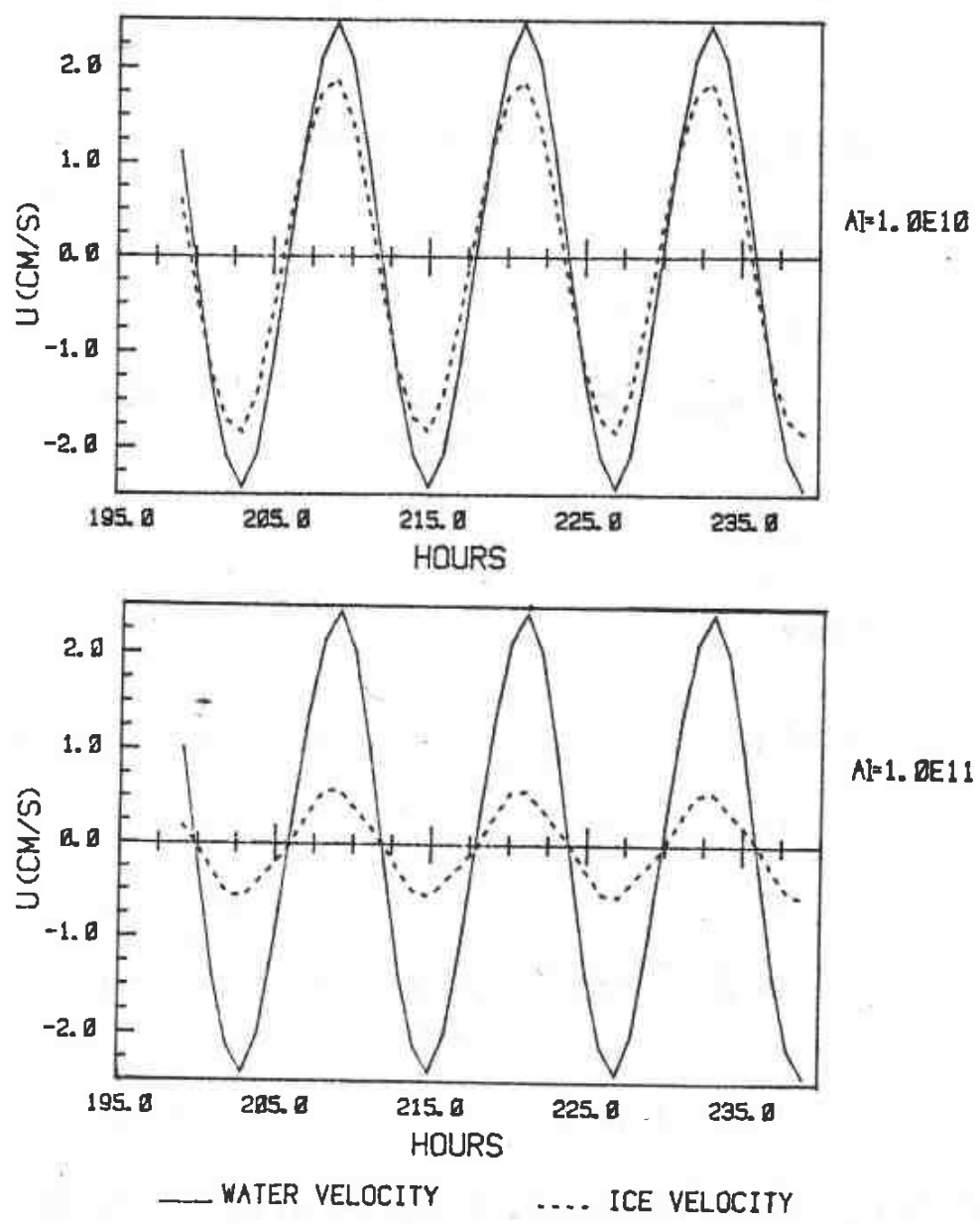

Figure 8. Water and ice velocity in the Barents Sea (position $74^{\circ} \mathrm{N}, 34^{\circ} \mathrm{E}$ ), computed using the linear viscous model of ice floe interaction. Eddy viscosity of water $A=5 \times 10^{8}$ $\mathrm{cm}^{2} / \mathrm{s}$, ice friction coefficient, $A I=10^{10} \mathrm{~cm}^{2} / \mathrm{s}$ (upper part), $A I=10^{11} \mathrm{~cm}^{2} / \mathrm{s}$ (lower part), water drag coefficient $R=5.5 \times 10^{-3}$.

A comparison of these results and these found by Campbell (1965) and Rothrock (1975) for the wind-driven motion of pack ice gives surprisingly good agreement of both values.

The linear viscous model is not compatible with our understanding of ice, therefore, series of experiments on tide-ice interaction, with the full non-linear constitutive law (14), will be performed. In the first experiment $A P$ was fixed at $10^{10} \mathrm{~cm}^{2} / \mathrm{s}$ which is well below the above range; in the next experiment $A P$ was increased to $10^{11} \mathrm{~cm}^{2} / \mathrm{s}$. The change due to the variation of this parameter, as can be seen from Fig. 9, is very considerable. The course of the water velocity around the mean value is completely symmetrical. The ice velocity, on the other hand, depicts asymmetry; small when $A P=10^{10} \mathrm{~cm}^{2} / \mathrm{s}$, and considerable when $A P=10^{11} \mathrm{~cm}^{2} / \mathrm{s}$. All the results we have presented are from the point inside the Barents Sea, so to provide a comparison, Fig. 10 gives the results, from the point close to the entrance to the White Sea. The 


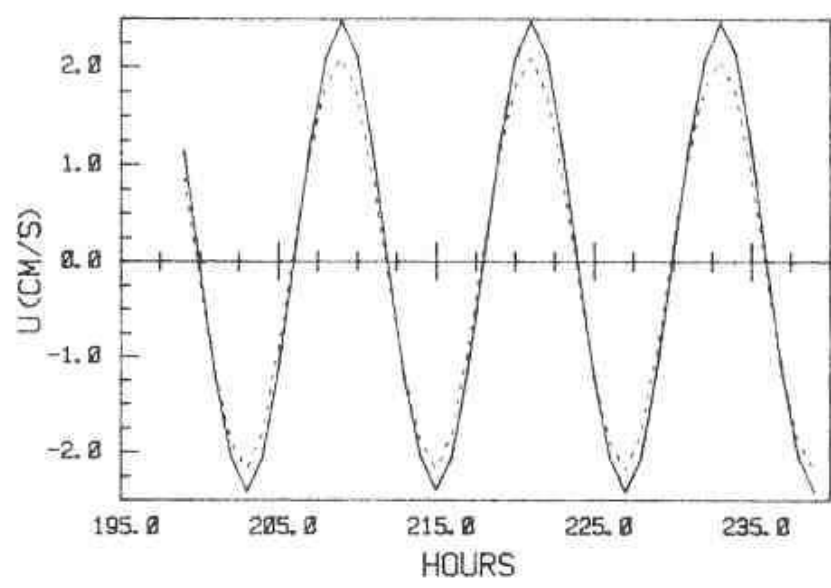

$A=5.8 E B$

$A I=1.6 E 9$

$A P=1$. DE 10

$A=3.8 E-3$

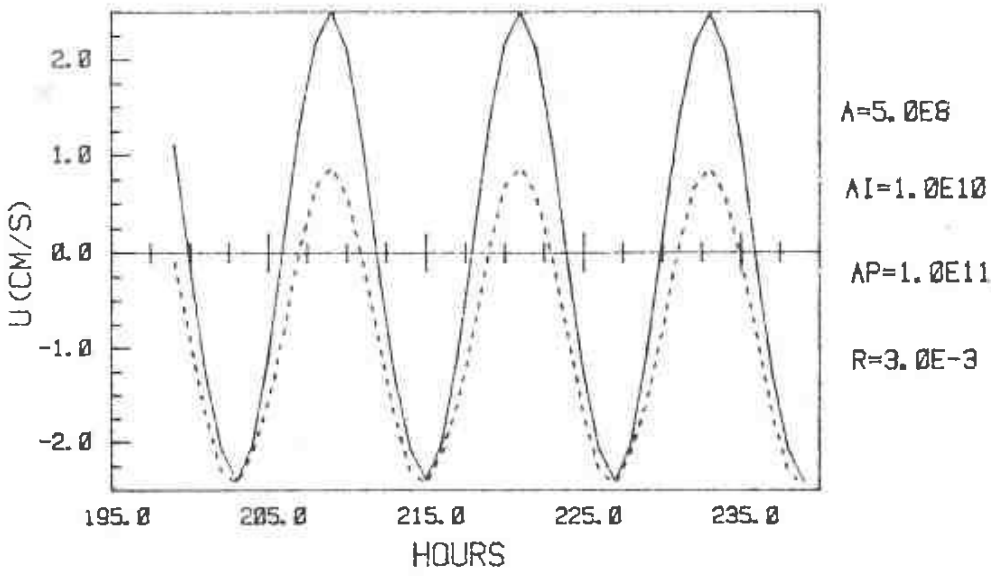

_._. WATER VELOCITY

ICE VELOCITY

Figure 9. Wat er and ice velocity in the Barents Sea (position $74^{\circ} \mathrm{N}, 34^{\circ} \mathrm{E}$ ), computed using the non-linear viscous model of ice floe interaction. Eddy viscosity of water $A=5 \times 10^{8}$ $\mathrm{cm}^{2} / \mathrm{s}$, ice friction coefficient, $A I=10^{9} \mathrm{~cm}^{2} / \mathrm{s}$ (upper part), $A I=10^{10} \mathrm{~cm}^{2} / \mathrm{s}$ (lower part), pressure coefficient, $A P=10^{10} \mathrm{~cm}^{2} / \mathrm{s}$ (upper part), $A P=10^{11} \mathrm{~cm}^{2} / \mathrm{s}$ (lower part), water drag $R=3 \times 10^{-3}$.

effect of tide-ice interaction is different in both figures. One has to remember that the ice motion induced by tides is not only due to the set of parameters chosen in the constitutive law; it depends also on the relative motion of ice and water. One conclusion from the above figures follows clearly: if the ice velocity is averaged over the tide period, the residual ice motion will be present. Therefore, due to nonlinear ice mechanics, tides induce a permanent pack ice circulation. Residual ice motion in the Arctic Ocean is plotted in Fig. 11. The magnitude of the ice velocity is rather small; over a large area of the Central Basin and along the coast of Greenland and Alaska, the values are below $0.1 \mathrm{~cm} / \mathrm{s}$. Velocities of several $\mathrm{cm} / \mathrm{s}$ are seen in the White Sea and in the south-east part of the Barents Sea: another area of higher velocities is situated around the New Siberian Islands. An interesting conclusion which follows from the pattern of residual currents is that the ice motion induced by tides may lead to the quick clearing of ice from the White Sea during spring. Generally speaking, residual currents are a function of the ice strength and they 

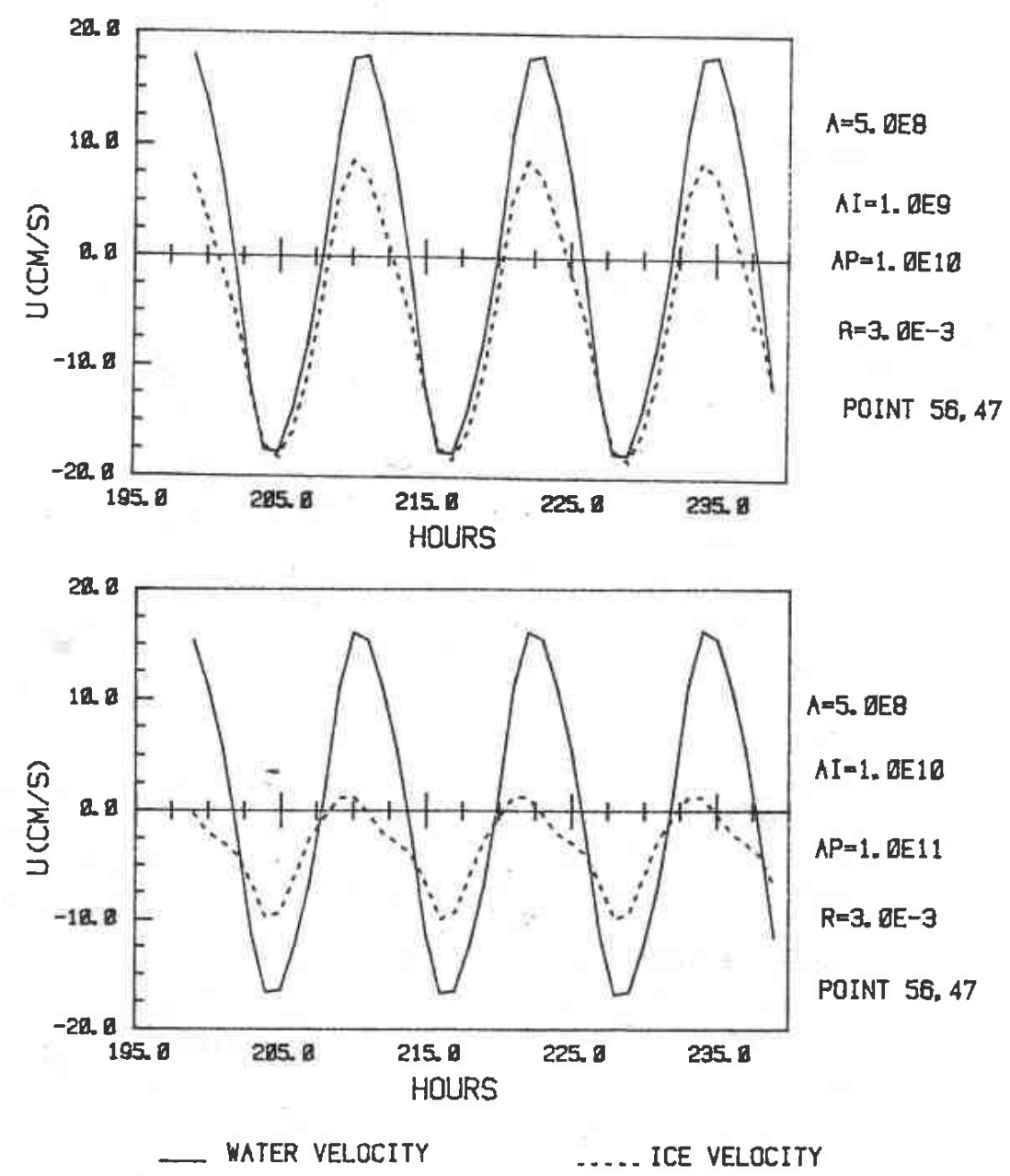

Figure 10. Water and ice velocity near the entrance to the White Sea, computed using the non-linear viscous model of ice flow interaction. Eddy viscosity of water $A=5 \times 10^{8}$ $\mathrm{cm}^{2} / \mathrm{s}$, ice friction coefficient, $A I=10^{9} \mathrm{~cm}^{2} / \mathrm{s}$ (upper part), $A I=10^{10} \mathrm{~cm}^{2} / \mathrm{s}$ (lower part), pressure coefficient, $A P=10^{10} \mathrm{~cm}^{2} / \mathrm{s}$ (upper part), $A P=10^{11} \mathrm{~cm}^{2} / \mathrm{s}$ (lower part), water drag $R=3 \times 10^{-3}$.

can be very small: A - in summer, when interaction between the ice floes is negligible, and $B$-in winter, when the ice is thick and internal stresses increase to large values. The pattern plotted in Fig. 11 thus represents the autumn or spring conditions. Finally, we have to stress that the parameters chosen for the computation of the residual ice motion are not strictly related to the ice strength encountered in nature, therefore, the picture may bear scant relation to the actual drift and should be accepted with certain caution.

A question may arise of whether residual ice motion can be observed in nature. It cannot be resolved properly without measurements of ice drift in the Barents Sea and particularly in the entrance of the White Sea. On the other hand, it is clear that the non-linear and elastic-plastic constitutive law should lead to the non-linear effects in pack ice movement. To confirm, at least partially, the results derived above, we have applied a viscoelastic constitutive law specified by Kheysin and Ivchenko (1973). Residual ice motion retains its previous character, and its value depends on the magnitude of the bulk modulus of ice elasticity. 


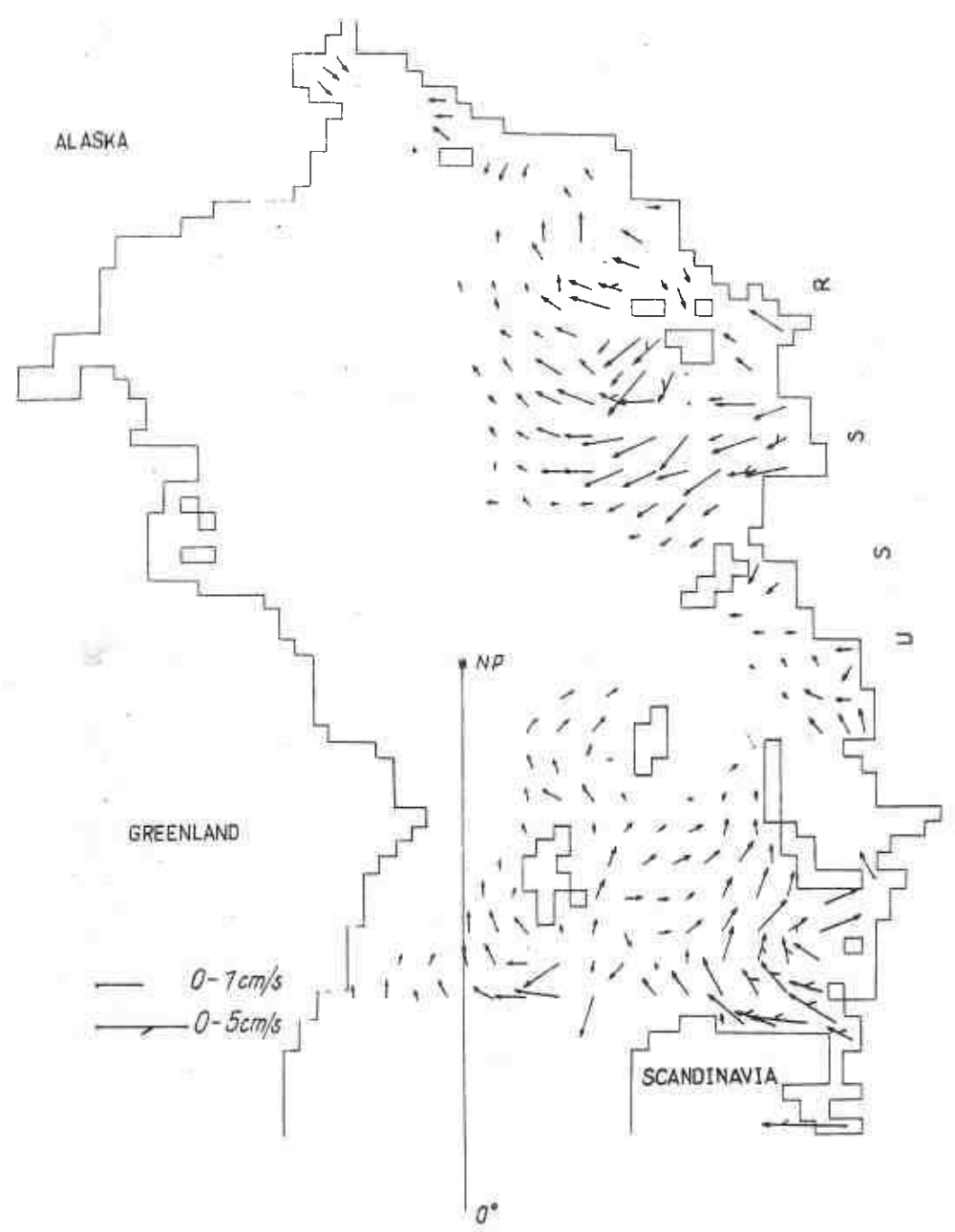

Figure 11. Residual (over $\mathrm{M}_{2}$ tide period) ice motion in the Arctic Ocean as a result of application of the non-linear constitutive law.

It is worthwhile to mention that along with residual ice motion, which is of transient character (in time), in shallow areas of strong tidal motion the permanent current is present due to non-linear tide interaction. In the Arctic Ocean, this phenomenon influences the pack ice motion along the south-eastern coast of the Barents Sea, in the White Sea, and probably in the vicinity of the New Siberian Islands.

Analysing, in turn, the tide distribution, it follows from all the figures that neither the linear nor non-linear model influence the tide distribution very much. The tide chart of the Arctic Ocean covered with ice, shown in Fig. 12, was based on the following set of parameters: $A=5 \times 10^{8} \mathrm{~cm}^{2} / \mathrm{s}, A I=10^{10} \mathrm{~cm}^{2} / \mathrm{s}, R=3 \times 10^{-3}$. The overall distribution is very close to that observed in Fig. 1 and Fig. 2, but the ice induces both phase lag and amplitude decay. In the areas of small tidal amplitude the variation is quite negligible, but in areas of strong tides, i.e. the south-eastern part of the Barents Sea and in the vicinity of the New Siberian Island, the amplitude change is several percent. 


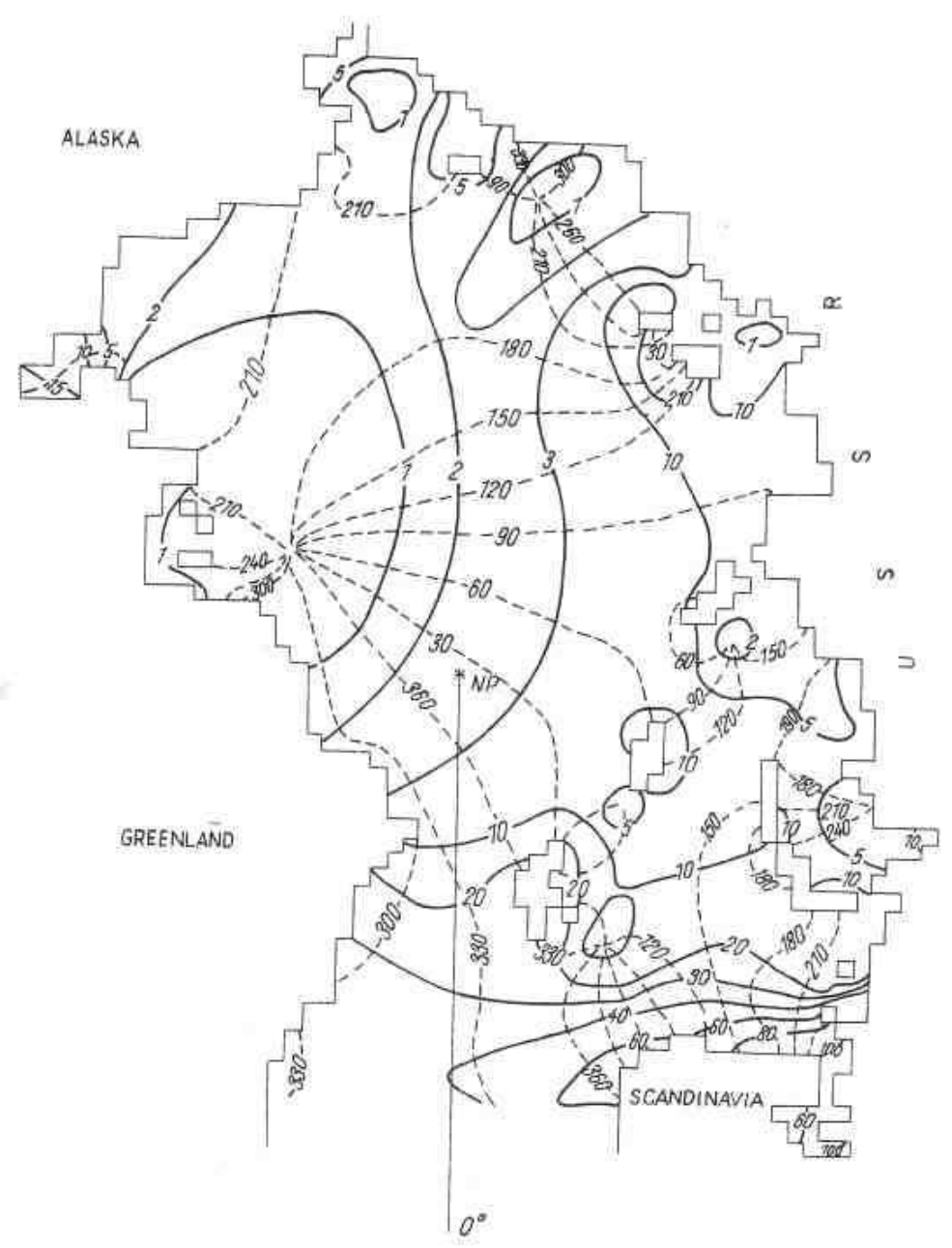

Figure 12. Co-tidal lines (dotted) and co-range lines (continuous) of the $\mathbf{M}_{2}$ tide in the ice-covered Arctic Ocean.

\section{Conclusions}

The $\mathrm{M}_{2}$-tide in the ice-free and ice-covered Arctic Ocean is studied through the system of non-linear equations (1-5). Numerical solution of the problem cannot be derived in a straight-forward manner, mainly because the pack ice has very high internal friction. Due to this fact, the stability condition of the explicit numerical scheme is reconsidered and the new condition is set by the inequality (9). An applied numerical scheme has better space resolution than the previous model of Kowalik and Untersteiner (1978), therefore it allows the tide entering from the Bering Sea and the White Sea area to be taken into account. The overall tide pattern in the Arctic Ocean remains the same, the new details appear in the near coastal zone. The main result of the ice-free model concerns the tide distribution in the Barents Sea. The comparison with the observations, also generally quite good, reveals in one of the amphidromic points and opposite rotation in the numerical model and in Sgibneva's (1964) observations. Our assumption is that Sgibnev's result might be erroneous due to scant tidal data.

To study tide propagation in the-ice-covered ocean, the non-linear viscous constitutive law is taken. First of all, since the law was not tested against the tide 
notion, is sequence of investigations was carried out to find the range of variability of the coefficients. The magnitudes derived are in surprisingly good agreement with the results found for the wind-driven motion of pack ice by Campbell (1965) and Rothrock (1975). The iufluence of the ice cover on the tide propagation leads to a time lag between the ice and water velocities and to decaying of the tide amplitude. The time lag is shown to be a complicated function of the ice frictional coefficients and the drag between water and ice. As the overall picture of the tide in the icecovered Arctic Ocean is very close to the pattern of the ice-free ocean, this confirms the small influence of ice on the long waves propagation.

As a by-product, due to the non-linear constitutive law, a residual (over the tide period) ice motion is obtained. Presently it is difficult to ascertain how important this transient phenomena could be, but together with the residual tide motion it can lead to the ice redistribution in the shallow areas of the Barents Sea, White Sea and in the vicinity of the New Siberian Islands.

\section{Appendix 1. Dissipation of the tidal energy}

Model of the ice-tide interaction developed for the Arctic Ocean allows us to solve a number of related problems. Jeffreys (1921) suggested that the tidal energy dissipation against the bottom is a principal cause of a secular acceleration of the moon. Now, we consider the dissipation of the tidal energy against the ice cover to supplement the results presented by Kowalik and Untersteiner (1978) for the ice-free Arctic Ocean. Energy dissipated is proportional to the scalar product of the stress and water velocity vector. In the ice-covered ocean the stress at the ice-water interface is present, along with the bottom stress, therefore, it is reasonable to assume that the ice may be responsible for higher energy dissipation. The actual situation is more complicated. We shall study this penomenon only through application of the linear frictional model. The energy dissipated in the whole Arctic Ocean per unit time (i.e. averaged over one $\mathrm{M}_{2}$ tide period) as a function of the different ice friction parameters is given in Table 2. If the ice friction coefficient $A I$ is close to the magnitude of the eddy viscosity coefficient of water-A, the velocity of both ice

\begin{tabular}{rccc}
\hline$A l\left(\mathrm{~cm}^{2} / \mathrm{s}\right)$ & $E_{b}(\mathrm{erg} / \mathrm{s})$ & $E_{i}(\mathrm{erg} / \mathrm{s})$ & $E_{b}+E_{i}(\mathrm{erg} / \mathrm{s})$ \\
\hline \multicolumn{4}{c}{$R=3 \times 10^{-3}$} \\
$5 \times 10^{8}$ & $1.2946 \times 10^{17}$ & - & $1.2946 \times 10^{17}$ \\
$10^{9}$ & $1.2946 \times 10^{17}$ & - & $1.2946 \times 10^{17}$ \\
$10^{10}$ & $1.1494 \times 10^{17}$ & $1.6087 \times 10^{16}$ & $1.3102 \times 10^{17}$ \\
$5 \times 10^{10}$ & $1.0924 \times 10^{17}$ & $4.1279 \times 10^{16}$ & $1.5052 \times 10^{17}$ \\
$10^{11}$ & $1.0264 \times 10^{17}$ & $5.012 \times 10^{16}$ & $1.5276 \times 10^{17}$ \\
\multicolumn{4}{c}{$R=5.5 \times 10^{-3}$} \\
$10^{9}$ & $1.2946 \times 10^{17}$ & - & $1.2946 \times 10^{17}$ \\
$10^{10}$ & $1.1131 \times 10^{17}$ & $0.10872 \times 10^{17}$ & $1.2218 \times 10^{17}$ \\
$5 \times 10^{10}$ & $8.9681 \times 10^{16}$ & $2.6025 \times 10^{16}$ & $1.1571 \times 10^{17}$ \\
$10^{11}$ & $8.1133 \times 10^{16}$ & $3 \cdot 1895 \times 10^{16}$ & $1.1303 \times 10^{17}$ \\
\hline
\end{tabular}

Tahle 2. Tidal energy (erg/s) dicsipated in the Arctic Ocean per unit time due to bottom friction $\left(E_{b}\right)$ and ice friction $\left(E_{i}\right)$ for different friction coefficients of the ice $(A I)$, constant eddy viscosity of water $A=5 \times 10^{8} \mathrm{~cm}^{2} / \mathrm{s}$, and two values of the water drag coefficient $R$. 
and water is close, and the water stress against ice is negligible. The overall dissipation is due only to bottom friction. An increase in the coefficient $A I$ causes an increase of dissipation at the ice-water interface. If $A I=10^{11} \mathrm{~cm}^{2} / \mathrm{s}$ and the drag coefficient at ice-water surface $R=3 \times 10^{-3}$, the overall dissipation increases by only $18 \%$ as compared to the ice-free ocean. In the second set of experiments when $R=5.5 \times 10^{-3}$ the overall dissipation even decreases and when $A I=10^{11} \mathrm{~cm}^{2} / \mathrm{s}$, its value is $11 \%$ small as compared to the ice-free ocean. It is clear, therefore, that the ice induces a higher dissipation which, on the one hand, leads to an increase in tidal energy dissipation against the ice but, on the other hand, it results in smaller water velocities. This in turn leads to a smaller amount of energy being dissipated against the bottom. Therefore, one may conclude that the amount of dissipated energy depends on the ice strength as expressed by the ice friction coefficient $A I$, on the aerodynamic properties of the ice-water surface expressed by the drag coefficient $R$, but it will not differ greatly from the dissipation in ice-free ocean.

From the above experiments, a situation somewhat closer to nature can be depicted in the following manner: the dissipation against loose ice is characterized by the second set of experiments, when the water drag is equal to $R=5.5 \times 10^{-3}$ and the frictional coefficients are in the range $A I=10^{8}-10^{9} \mathrm{~cm}^{2} / \mathrm{s}$. If the ice compactness increases, the dissipation is better described by the first set of experiments, with the water drag $R=3 \times 10^{-3}$ and the frictional coefficients in the range $10^{10}$ $10^{11} \mathrm{~cm}^{2} / \mathrm{s}$. The largest energy $E_{b}+E_{i}=1.527 \times 10^{17} \mathrm{erg} / \mathrm{s}$ is dissipated when the ice is assumed to be nearly perfectly rigid $\left(A=10^{11} \mathrm{~cm}^{2} / \mathrm{s}\right)$. The amount of energy dissipated in the ice itself is at least two orders smaller compared to $E_{b}+E_{l}$.

\section{Appendix 2. Maximal shear}

The process of tide propagation can be of practical significance to navigation through ice if it leads to the existence of openings (leads) or closings in the pack ice. A uniform deformation throughout the ice field does not set any openings. Therefore, it will be of interest to define, or to give a measure of the non-uniformity of deformation. The concept of maximal shear of water velocity (or, briefly, maximal shear) can serve this aim best. The magnitude of maximal shear $\left(V_{s}\right)$ is expressed in the following way (Kuznecov 1951),

$$
V_{s}=\left[\left(\frac{\partial u_{w}}{\partial x}-\frac{\partial v_{w}}{\partial y}\right)^{2}+\left(\frac{\partial u_{w}}{\partial y}+\frac{\partial v_{w}}{\partial x}\right)^{2}\right]^{1 / 2}
$$

The distribution of $V_{s}$ in the ice-free Arctic Ocean is plotted in Fig. 13. The most probable areas for the appearance of ice leads, where $V_{s}$ exceeds $10^{-6} \mathrm{~s}^{-1}$, are the Barents Sea and the coasts along Siberia, especially in the vicinity of the New Siberian Islands.

Numerical experiments in the ice-covered Arctic Ocean show that the ice does not influence greatly the distribution of maximal shear.

Phase of the maximal shear is coherent only over a distance shorter than 500 $700 \mathrm{~km}$.

In the paper by Kowalik and Untersteiner (1978) the possibility of ice redistribution by the tide motion was characterized by divergence of velocity. The maximal magnitude of shear (in present calculation) and maximal divergence (in previous calculation) are generally confined to the area of large velocities. The use of shear is related to the experimental fact discovered by Thorndike that the ice deformation is better reflected in shear than in divergence, see Rothrock (1975). 


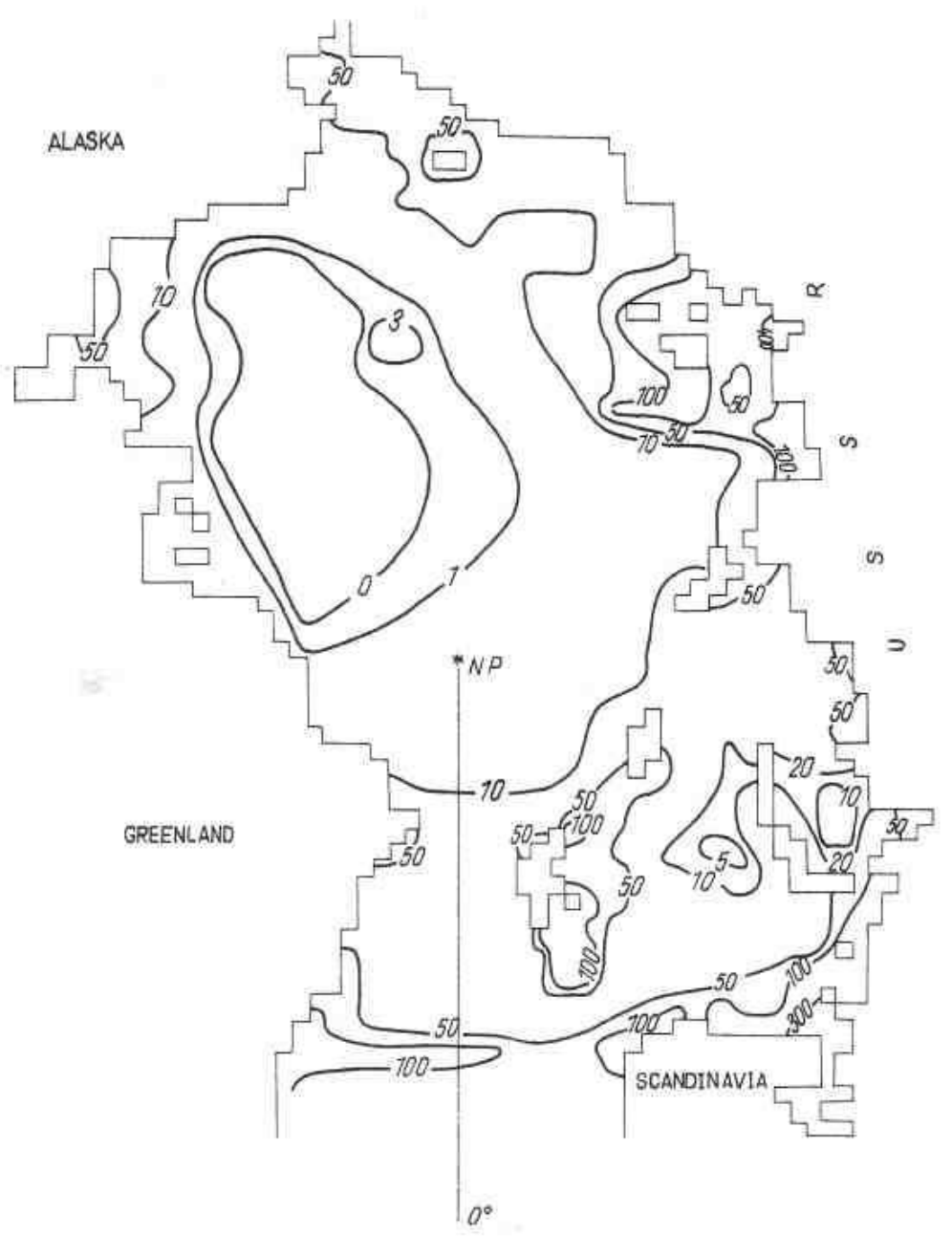

Figure 13. Distribution of maximal shear of water velocity in the Arctic Ocean due to the $\mathrm{M}_{2}$ tide. The numbers in the figure should be multiplied by $10^{-8} \mathrm{~s}^{-1}$.

\section{ACKNOWLEDGMENTS}

This work has been sponsored by The Royal Norwegian Council for Scientific and Industrial Research through the-research programme HAVBIOMODELLER (Ocean Bio-Models).

I wish to express my deep appreciation to Professor Jens G. Balchen and staff of the Division of Engineering Cybernetics, University of Trondheim for the fruitful discussions and generously offered help throughout the work.

I am also indebted to Professor Norbert Untersteiner, University of Washington, Seattle, who made most welcome comments towards improving my understanding of ice physics.

\section{REFERENCES}

Camprell, W. J. (1965). The wind-driven circulation of ice and water in a Polar Ocean. Journ. Geoph. Research, 70, 14, 3279-3301.

Coon, M. D., Maykut, G. A., Pritchard, R. S., Rothrock, D. A., and Thorndike, A. S. (1974). Modeling the pack ice as an elastic-plastic material. AIDJEX Bulletin, 24, 1-105. 
Glen, J. W. (1970). Thoughts on a viscous model for sea ice. AIDJEX Bulletin, 2, 18-27.

HANSEN, W. (1962). Hydrodynamical methods applied to the oceanographical problems. Proc. Symp. Math.-Hydrodyn. Meth. Phys. Oceanography. Mitt. Inst. Meeresk., Univ. Hamburg, 1, 25-34.

Hibler III, W. D. (1979). A dynamic thermodynamic sea ice model. J. Phys. Oceanogr., 9, 815-846.

Hunkins, K. (1967). Inertial oscillations of Fletcher's Ice Island (T-3). J. Geoph. Rcs., 72, $4,1165-1174$.

Jefrereys, H. (1921). Tidal friction in shallow seas. Philos. Trans. R. Soc. London (A), 221, 239-264.

KAGAN, B. A. (1968). Hydrodynamical models of tidal motion in the sea (Gidrometeoizdat. Leningrad), pp. 218.

KaGAN, B. A. (1970). On the features of some finite-difference schemes used at numerical integration of tidal dynamics equations. Izv. Atmospheric and Oceanic Physics, 6, 7, 704-717.

Kheysin, D. Y., and Ivchenko, V. O. (1973). A numerical model of tidal ice drift with allowance for the interaction between floes. Izv. Atmospheric and Oceanic Physics, $9,4,420-429$.

Kowalik, Z. (1979). A note on the co-oscillating $\mathrm{M}_{2}$-tide in the Arctic Ocean. Dt. Hydrogr. Zt., 32, H.3, 100-112.

Kowalik, Z., and Bich HuNG, N. (1977). On a system of hydrodynamic equations for certain oceanographical problems in the region of the earth's pole and the stability of its solution. Oceanologia, 7, 5-20.

KowaliK, Z., and UNTERSteiner, N. (1978). A study of the $\mathbf{M}_{2}$ tide in the Arctic Ocean. Dt. Hydrogr. Zt., 31, H.6, 216-229.

KuZNeCov, D. S. (1951). Hydrodynamics (Gidrometeoizdat. Leningrad), pp. 392.

LEGENKOV, A. P. (1958). On the theory of tidal concentration, dispersion and compaction of ice in open sea. Probl. Arkt. Antarkt., 5, 5-17.

Ling, C. H., Rasmussen, L. A., and Campbell, W. J. (1980). A continuum sea ice model for a global climate model. In Proceedings of the AIDJEX Symposium (University of Washington Press), pp. 187-196.

Marchux, G., GoRdev, R., Kagan, B., et al. (1972). Numerical method to solve tidal dynamics equation and results of its testing (Novosybirsk: Comput. Centre), pp. 78.

McPhee, M. G. (1980). An analysis of pack ice drift in summer. In Proceedings of the AIDJEX Symposium (University of Washington Press), pp. 62-75.

Nekrasov, A. V. (1975). Tidal waves in the adjacent seas (Gidrometeoizdat. Leningrad), pp. 247.

Pritchard, R. S., (ed.) (1980). Sea Ice Processes and Models. Proceedings of the AIDJEX Symposium (University of Washington Press), pp. 474.

RAMming, H-G., and KowALIK, Z. (1980). Numerical modelling of marine hydrodynamics (Elsevier. Amsterdam-New York), pp. 148-154.

Rothrock, D. A. (1970). The kinematics and mechanical behaviour of pack ice: the state of subject. AIDJEX Bulletin, 2, 1-10.

RoTHRock, D. A. (1975). The mechanical behaviour of pack ice. Annual Review of Earth and Planetary Sciences, 3, 317-342.

SGibneva, L. A. (1964). Tides in the Barents Sea. Trudy Okiean. Instituta, 75, 5-19.

Sodhi, D. S., and HiBler III, W. D. (1980). Nonsteady ice drift in the Strait of Belle Isle. In Proceedings of the AIDJEX Symposium (University of Washington Press), pp. 177-186.

SündermanN, J. (1970). The semi-diurnal principal lunar tide $M_{2}$ in the Bering Sea. Dt. Hydrogr. Zt., 23, H.3, 91-101.

TAYLOR, G. I. (1921). Tidal oscillations in gulf and rectangular basins. Proc. London Math. Soc. Ser. 2, 20, 148-181.

TEE, K. T. (1976). Tide-induced residual current, a 2-D nonlinear numerical tidal model. J. Mar. Res., 4, 603-628.

ZuBov, N. N. (1955). Selected works on oceanology (Voenoye Izd. Moscow), pp. 266-270. 